\title{
Laura Snell: Studying the wild horses of northeastern California
}

\author{
-his September, the U.S. Forest Service (USFS), in \\ partnership with Modoc County and the U.S. Bureau \\ of Land Management (BLM), conducted the first
} major roundup of wild horses on Devil's Garden Plateau since 2006. The state's largest population of wild horses is found here, on a high-desert expanse of Modoc National Forest surrounded by private ranchland and tribal lands. A survey in February estimated 2,246 horses here, far above the target of 206 to 402 adult wild horses established by the 2013 management plan for the 230,000 acres of designated wild horse territory on the plateau.

\section{UCCE Modoc County advisor Laura Snell and USFS rangeland management specialist Jenny Jayo mount a wildlife monitoring camera at Bottle Springs, a water source in Modoc National Forest.}

Through 2006, the Devil's Garden horse population had long been stabilized at a few hundred adults through regular roundups, called gathers, which removed horses from the range every year or two. Since then, a combination of legal challenges to federal wild horse management plans and difficulty securing funding stopped large gathers.

That allowed the population to balloon, with horses stressing grazing allotments on USFS land and straying onto private and tribal lands.

As the horse herds and their impacts on rangelands have grown, it has ratcheted up tensions among ranchers, wild horse advocates, hunters, recreational users and local officials - and the federal land managers charged with adjudicating the use of the Devil's Garden rangelands.

"This is the most controversial research I've ever been involved in," said livestock and natural resources advisor Laura Snell, who joined UC Cooperative Extension (UCCE) in 2015. "I had Modoc County ranchers coming up to me on my second day of work asking me how to solve the wild horse issue."

In partnership with USFS range management specialists, UCCE Lassen County director David Lile and UC Davis-based UCCE specialist Roger Baldwin, Snell is collecting new photographic data on a key area of dispute in the wild horses debate: the impact horses have on rangeland vegetation and soils, especially around water sources, and on other wildlife.

"We can't just take vegetation data, we need the visuals to show people what's going on," she said.

The study, begun in 2015 and scheduled to continue at least through 2017, uses wildlife cameras placed for two-week periods at 24 remote water

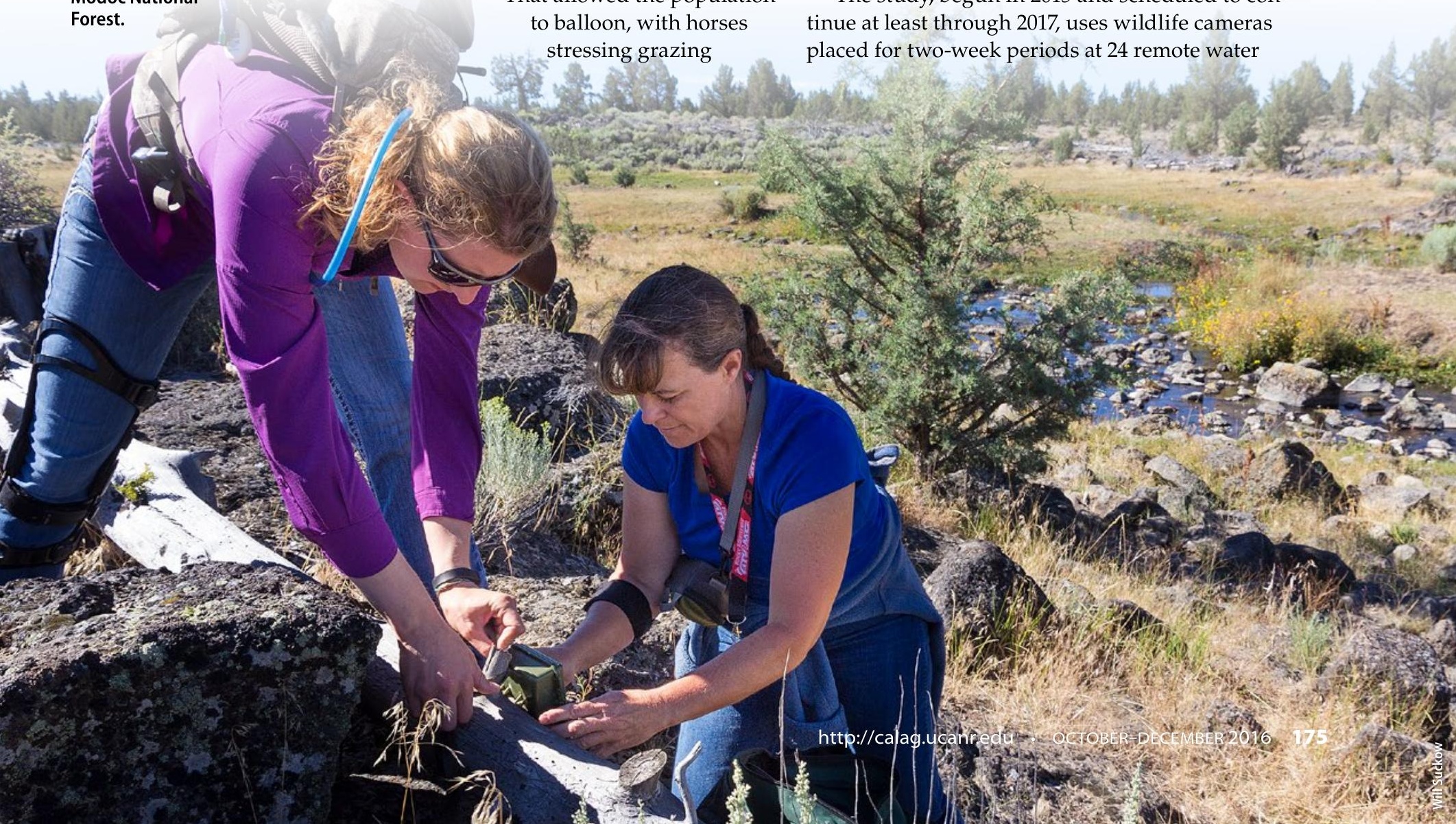




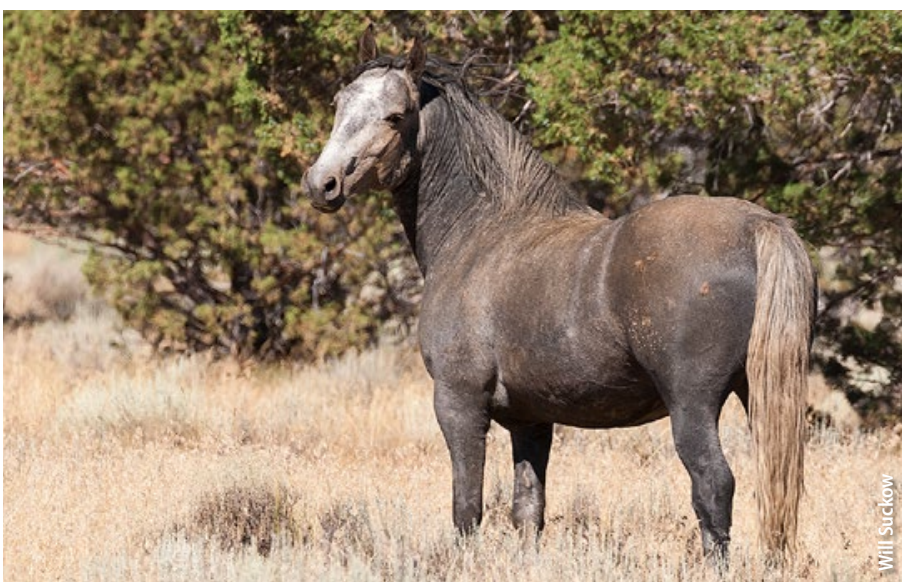

A wild stallion on Devil's Garden Plateau.

school. For her master's thesis, she studied multi-use grazing in Namibia.

One thing that attracted her to UCCE, Snell said, was the chance to have an academic job based in a rural community, with the prospect of remaining in the same county for her entire career.

The wild horse issue certainly appears to be one that will demand attention for years to come in Modoc County and other communities across the West.

A 1971 federal law mandates that wild horses and burros be "protected, managed and controlled" on public lands by the BLM to allow for coexistence with wildlife and livestock. But with few natural predators, unmanaged wild horse populations can grow $20 \%$ per year - leading quickly to conflicts with the other uses of the land that the government is obliged to protect. Today, the combined number of wild horses and burros - about 55,000 and 12,000, respectively - is two and a half times the "appropriate management level" established by the federal government. Wild horses in the West are not native - genetic studies indicate that they are descended from released or abandoned domestic horses (NRC 2013).

Many horse advocacy groups push for a hands-off approach, arguing that the populations should be allowed to expand until limited by factors like predation and food supply — though a number of groups also support measures to reduce fertility. Ranchers, hunting groups and some wildlife advocates, on the other hand, argue that the horses need to be physically removed through gathers to protect the rangeland for other uses.

A gather like the one conducted in September, which removed 200 horses from private and tribal land adjacent to Modoc National Forest land, costs about $\$ 800,000$. The work is done by a specialty contractor that uses helicopters to herd the animals into temporary corrals and also manages, in partnership with the USFS and BLM, an array of other logistics, including providing viewing platforms for horse advocates. Wild horse groups generally oppose gathers, arguing that they overstress the animals and break up family structures in the herds.

While gathers are expensive to conduct, even more costly is taking care of the horses once they are taken off the range. The captured horses are made available for adoption, but the great

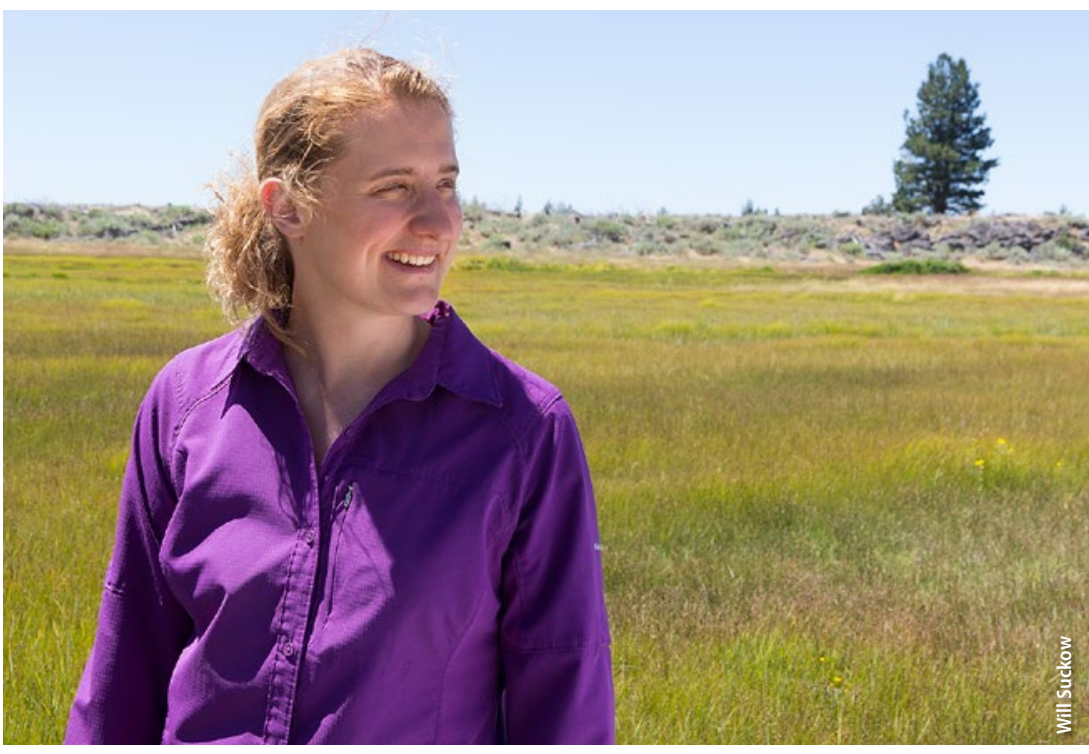

Laura Snell near another monitoring site.

majority - now a total of 46,000 horses and burros - are not claimed and end up in BLM-funded care on private ranches, generally in the Plains states. Supporting these animals consumes two-thirds of the BLM's $\$ 75$ million federal budget for wild horse management, and it puts the agency in a bind: Spending more to remove additional horses from the range will increase the cost to care for the off-range horses.

Wild horses have a powerful emotional appeal, and that greatly complicates their management (NRC 2013). In September, a citizens panel that advises the BLM recommended that the agency kill significant numbers of its off-range horses to save money so that it could better manage horses in the wild. But public outcry was instant, and as the committee's recommendation grew quickly into a national news story, the BLM hurried to issue statements that it would not be killing any horses.

Fertility control for horses on the range may eventually be a useful management tool. But the current method, a vaccine called PZP that can be injected by a rifle dart and temporarily renders mares infertile, is effective for only a year - meaning that many thousands of horses would have to be darted annually to shrink the herds.

There is official recognition that the current situation is unsustainable. In late October, a report from the inspector general of the Department of the Interior found that BLM lacks a strategic plan to satisfactorily address either the expanding on-range populations or the growing expense of holding the animals off-range. CA

\section{-Jim Downing}

\section{Reference}

[NRC] National Research Council. 2013. Using Science to Improve the BLM Wild Horse and Burrow Program: A Way Forward. Washington: The National Academies Press. https://doi.org/10.17226/13511 